Portland State University

PDXScholar

\title{
Sex Differences in Prevalence and Psychophysiological Profiles of ADHD
}

McKenzie Figuracion

Portland State University

Follow this and additional works at: https://pdxscholar.library.pdx.edu/honorstheses

Part of the Mental Disorders Commons, and the Psychology Commons Let us know how access to this document benefits you.

\section{Recommended Citation}

Figuracion, McKenzie, "Sex Differences in Prevalence and Psychophysiological Profiles of ADHD" (2020). University Honors Theses. Paper 916.

https://doi.org/10.15760/honors.938

This Thesis is brought to you for free and open access. It has been accepted for inclusion in University Honors Theses by an authorized administrator of PDXScholar. Please contact us if we can make this document more accessible: pdxscholar@pdx.edu. 


\section{Sex Differences in Prevalence and Psychophysiological Profiles of ADHD}

By

McKenzie Figuracion

An undergraduate honors thesis submitted in partial fulfillment of the requirements for the degree of

Bachelor of Science

In

University Honors and Psychology

Thesis Advisor:

Sarah Karalunas, PhD

Portland State University 


\section{ABSTRACT}

Background: Considerable research has been dedicated to understanding the etiology of Attention-Deficit/Hyperactivity Disorder (ADHD), but the focus has been on a homogenous subset of the population, and multiple groups go underserved when it comes to support. Previous findings suggest differences in ADHD diagnosis and referral rates based on sex, but it is less clear whether neurophysiological sex differences exist. The current study examines the effect of expert consensus diagnostic practices on rates of diagnosis in males and females and evaluates sex differences in potential neurophysiological markers of ADHD.

Methods: 860 children and adolescents $($ Males=519; $\mathrm{ADHD}=516)$ were recruited for a longitudinal study. Parents reported whether their child had an ADHD diagnosis from a community practitioner. Children then underwent comprehensive evaluation and a diagnostic team made a consensus diagnosis based on available data. A subset of children $(n=272$, $\mathrm{ADHD}=162$ ) also completed 32-channel resting-state EEG assessment.

Results: Males were significantly more likely than females to have received a prior ADHD diagnosis and were also more likely to receive an expert consensus diagnosis of ADHD. Females with ADHD had significantly more inattention symptoms than males with ADHD; there was no sex effect for hyperactive symptoms. There was a marginal sex effect on frontal alpha asymmetry, but no other significant effects. Posterior analysis yielded similar results. Conclusions: Results confirm significant sex differences in rates of ADHD diagnosis in both community and expert consensus diagnosis. There may also be a sex effect on alpha asymmetry and sex-specific biomarkers require further evaluation. 


\section{Introduction}

Attention Deficit/Hyperactivity Disorder (ADHD) is a common psychiatric disorder found in both children and adults with prevalence estimates currently at $4.4 \%$ in adults (Kessler et al., 2007) and $8.7 \%$ in children aged 8 to 15 years old (Froehlich et al., 2007). Due to the prevalence of this disorder, much research has been devoted to understanding the etiology of ADHD. However, despite decades worth of research, there has been a historical tendency to focus on a homogenous subset of those diagnosed with ADHD: Caucasian males (Gershon, 2002). Due to this, there is difficulty in generalizing findings to the larger population, and this has led to other groups going unnoticed or underserved when it comes to support and treatment. Females are one such subset of the population and this sex bias has had far-reaching consequences (Quinn, 2008).

\section{Who is Diagnosed with ADHD?}

In literature conducted to date, there are two common ways that ADHD research samples are collected: through clinics and through the community. In clinic-referred samples, the participants are recruited after they present to a clinic for formal diagnosis. In contrast, in community-based samples participants are recruited through broad outreach, irrespective of prior diagnosis or the seeking of services. In community-based samples of youth with ADHD, there is approximately a 3:1 male to female ratio for diagnosis (Willcutt, 2012) but this ratio climbs to 9:1 in clinically-referred samples (American Psychiatric Association, 1994). Discrepancies between community and clinic-referred samples suggest that many females with ADHD would meet criteria for diagnosis, yet they are rarely presenting to clinics to receive formal diagnosis and treatment (Gershon, 2002). 
One explanation for this discrepancy is referral bias, a type of selection bias that increases the likelihood of a certain outcome as a result of which participants are referred to the study; this has mainly been observed in clinic-referred samples (Gershon, 2002). In ADHD, the symptom presentation of females may contribute to referral bias. Two meta-analyses have been conducted to date that review sex differences in ADHD and they have general agreement with one another (Gaub \& Carlson, 1997; Gershon, 2002). Though methodological problems may have influenced conclusions in the first meta-analysis (such as stringent inclusion criteria, a small sample size, and referral bias), the subsequent meta-analysis came to a similar conclusion despite changes in methodology (Gershon, 2002). Both meta-analyses concluded that females with ADHD show fewer primary symptoms than their male counterparts. This was true in both clinic-referred and community-based samples. Females with ADHD were also specifically rated as less hyperactive and impulsive than males with ADHD on both parent and teacher reports. Because hyperactive-impulsive behaviors are most disruptive in an educational setting, this difference in symptom presentation may explain why females are under-recognized in school settings and not referred for formal clinical diagnosis as often (Gaub \& Carlson, 1997).

Interestingly, teachers also rated females with ADHD as having fewer inattentive and externalizing symptoms than males with ADHD, even though parent ratings of males and females did not differ for inattention or externalizing behavior (Gershon, 2002). Teachers also typically rated males as significantly more impaired compared to the same child's parents. One possibility is that teachers attend most to disruptive behaviors in the classroom and under-recognize inattentive symptoms, thereby contributing to the under-identification of females in the ADHD referral and diagnostic process. With clinics receiving the most referrals 
from schools (Gershon, 2002), this could explain why so few females present to clinics for formal clinical diagnoses compared to their male counterparts.

Although clinic-referral bias undoubtedly plays a role in females with ADHD being under-recognized for clinical services, it is less clear what explains sex differences in community samples. Results from multiple community-based samples of ADHD have eliminated selection bias as a possible explanation for differences between the sexes in their samples (Graetz et al., 2001; Willcutt, 2012; Willcutt, 2015) and have proposed that there is a valid discrepancy between the number of males and females who have the disorder. However, there are other factors that may complicate ADHD diagnosis in females.

In addition to differences in core ADHD symptom presentation, females also generally score higher on internalizing problems (Quinn, 2008; Gaub \& Carlson, 1997; Gershon, 2002) than their male counterparts, suggesting that comorbid negative affect conditions may be more common in females. It is well known that ADHD is associated significantly with comorbidities, and approximately $70 \%$ to $75 \%$ of adults diagnosed with ADHD also present with at least one additional diagnosis (Wilens, Biederman \& Spencer, 2002). However, negative affect comorbidities are seen more in females than males within this psychiatric disorder; females exhibit greater psychological distress and are reported to have more anxiety, overall distress, and depressive symptoms than ADHD males as well (Rucklidge \& Tannock, 2001). Skogli et al. (2013) came to similar conclusions which show that in self-report measures, females report higher rates of anxiety symptoms in ADHD. The presence of these mood and anxiety symptoms may then overshadow, complicate, and even delay ADHD diagnosis, and symptoms for ADHD in females can be missed altogether because of this (Quinn, 2008). Clinic-referred females with 
ADHD also tend to show more severe internalizing symptoms and may not be representative of females with ADHD as a whole (Biederman et al., 2002; Biederman et al., 2008), but it is less clear how the presence of comorbid mood or anxiety disorders may affect diagnosis in community recruited samples.

The current study uses a large, well-characterized, community-recruited sample of children to characterize sex-based differences in rates of ADHD diagnosis. Our analyses compare rates of prior diagnosis based on referral to clinics with rates of diagnosis by an expert panel trained to take into account variation in symptom presentation (inattentive versus hyperactive-impulsive symptoms) and co-occurring disorders. We hypothesize that there will be a large discrepancy between the number of males and females previously referred to clinics and diagnosed with ADHD, but that difference will be smaller using the expert consensus panel that can account for factors contributing to referral bias and difficult differential diagnosis.

\section{Sex Differences in Psychophysiological Measures}

An additional explanation for sex differences in rates of ADHD diagnosis that remain after accounting for differences in clinic-referral rates and variations in symptom presentation is that males and females have differential biological risk profiles. Because ADHD is known as an extremely heterogeneous disorder, ADHD research now is increasingly focused on identifying endophenotypes for the disorder — markers of disorder liability or severity that are directly related to etiology and developmental course. As such, endophenotypes have the potential to aid in more accurate diagnoses and specialized treatment for ADHD. However, it is imperative that we also consider differences in sex when it comes to these endophenotypes as these may differ in males and females with ADHD. 
There are many proposed endophenotypes in ADHD, such as ones related directly to cognition and executive function (Arnett et al., 2015; Seidman, 2005; Rucklidge, 2010). Additional endophenotypes of interest are psychophysiological; these measure cortical and autonomic nervous system activities, including magnetic resonance imaging (MRI), electroencephalogram (EEG), and electrodermal activity (EDA) (Hermens et al., 2005).

Many neuroimaging studies, specifically those using MRI, have shown both structural and functional differences between children with and without ADHD; some differences have also been shown between the sexes of those who are diagnosed with ADHD (Scofield et al., 2019; Konrad \& Eickhoff, 2010; Cao et al., 2014). In terms of functional connectivity, sex differences have been found in both the DMN and sensorimotor cortices (Biswal et al., 1996; Ritchie et al., 2018). Males also tend to be more variable when it comes to neural patterns (Scofield et al., 2019), as well as in cognition and behavior domains (Hedges \& Nowell., 1995; Johnson \& Bouchard, 2007). Lastly, there have been findings that suggest sex differences in both static functional connectivity (Ritchie et al., 2018) and dynamic state changes (Scofield et al., 2019). However, it remains unclear whether found sex differences in MRI studies is because of innate difference or the reflection of societal gender roles.

Previous psychophysiological studies of sex differences in EEG have found similar results showing that that males produce greater EEG abnormalities (Clarke et al., 2001) and a greater enhancement of low-frequency EEG activity (Hermens et al., 2004). Additionally, one proposed EEG psychophysiological endophenotype for ADHD that may differ based on sex is atypical frontal brain laterality, also known as frontal alpha asymmetry. These EEG patterns are measured as the difference in alpha band power between right and left frontal electrode 
locations. Greater left frontal asymmetry is associated with negative emotions and withdrawal behaviors and greater right frontal asymmetry is associated with positive emotions and approach behaviors (Coan \& Allen, 2003; Davidson, 2004).

Alpha asymmetry patterns have also been associated with emotional symptoms in ADHD, specifically that a leftward asymmetry is associated with negative emotions and may be moderated by the presence of negative affective disorders (Alperin et. al., 2019). Frontal alpha asymmetry is a promising marker for ADHD because of its connection to the approach-withdrawal model that seeks to either maximize reward and minimize punishment (approach) or avoid non-rewarding or aversive situations (withdrawal) (Davidson et al., 1990; Harmon-Jones \& Allen, 1997; Harmon-Jones et al., 2011), suggesting that right frontal alpha asymmetry in ADHD may be a promising endophenotype to study as this reflects increased approach related behaviors common in this disorder (Mitchell, 2010; Keune et al., 2015; Ellis et al., 2017; Alperin et al., 2019). Lastly, while most studies focus on frontal regions, some have also studied differences in alpha asymmetry at posterior sites in the brain (Hale et al., 2009, 2010; Alperin et al., 2019) though findings are inconsistent.

However, if females with ADHD are less likely to show the hyper-impulsive approach symptoms and more likely to have comorbid internalizing disorders (which are associated with left rather than right asymmetry), alpha asymmetry may not be as important as a marker of ADHD in this group. Previous studies on alpha asymmetry have found that results may be moderated by factors such as comorbidity and sex. This is of interest as females are more likely to experience comorbid negative affective disorders which is associated with a withdrawal system and therefore a more leftward alpha asymmetry rather than the expected rightward alpha 
asymmetry in ADHD. However, it remains unclear if a significant sex effect exists in alpha asymmetry as previous literature has found mixed results.

\section{Implications}

Sex differences in psychopathology have been understudied in psychological research even though awarding heightened attention to this topic would be beneficial to the field (Hartung \& Lefler, 2019). What we do know about sex differences is not as strong as it could be and psychopathological research has only recently begun to focus on females. What has been found in literature proves that there are noticeable sex differences in both diagnosis and referral rates in ADHD, but potential explanations for this difference as well as possible sex-specific endophenotypes for the disorder require further evaluation and research; this could have several impacts. First, understanding both sex differences and similarities would influence development of effective assessment and treatment methods (Hartung \& Lefler, 2019). This understanding could give clinicians and psychiatrists the ability to more accurately diagnose and treat patients.

Second, studying sex differences in psychopathology would impact the development of etiological theories as well (Hartung \& Lefler, 2019). Our understanding of sex differences in ADHD is not as strong as it should be and studying this further has the ability to aid in identifying endophenotypes, help create effective and individualized treatments, and strengthen our understanding of the etiology of ADHD.

\section{Current Study}

With minimal research dedicated to females with ADHD (Gaub \& Carlson, 1997) our understanding of sex-sensitive profiles is limited, in turn limiting our understanding of ADHD etiology and associated endophenotypes for the disorder, as well as how this may differ between 
the sexes. The current study aims to see if previous results related to sex differences in community and clinically referred samples can be replicated and will also investigate if frontal alpha asymmetry patterns differ between the sexes. Based on prior literature on clinically-referred samples, it is hypothesized that there will be significant sex based differences present in the sample who received a previous ADHD diagnosis, and less of a sex difference in children who receive an expert consensus diagnosis. Additionally, the study will add to relatively sparse literature on alpha asymmetry in ADHD by investigating whether sex differences exist, though there is no clear hypothesis based on previous findings.

\section{METHODS}

\section{Participants}

860 children $(\mathrm{ADHD}=516)$ were recruited for a longitudinal ADHD study. A community-based strategy was used to recruit individuals which included both public advertising and broad community outreach. Recruitment specifically targeted children both with and without developmental concerns and was not limited to those with a prior diagnosis (or suspected diagnosis) of ADHD. Approval for the study was obtained through the Institutional Review Board located at Oregon Health \& Science University and the study obtained informed consent from a parent or legal guardian along with written assent from participating children.

After a phone screen, standardized rating scales were completed by a parent/guardian as well as a teacher which included the Conners' Rating Scales (Conners, 2001), Strengths \& Difficulties Questionnaire (Goodman, 2002), and the ADHD Rating Scale (ADHD-RS) (DuPaul et al., 1998). Additionally, a parent or legal guardian completed a semi-structured clinical interview administered by a clinician. Children also completed the Children's Depression 
Inventory (Kovacs, 1985) and the Multidimensional Anxiety Scale for Children (March et. al., 1997). Child IQ was estimated based on a reliable and valid three-subtest short form of the WISC-IV (Vocabulary, Block Design, and Information, Sattler \& Dumont, 2004; Wechsler, 2003). Academic achievement was assessed using the Word Reading and Math Reasoning subtests of the WIAT-II (Wechsler, 2002).

Final diagnoses (either "control” or "ADHD," as well as all comorbid diagnoses) were made by a clinical diagnostic team (a board-certified child psychiatrist and licensed clinical child psychologist), who took into account data from the parent and teacher ratings, parent KSADS interview, IQ, and achievement testing, and interviewer and tester observational notes. They formed initial diagnostic assignments blind to one another's ratings. Their blind agreement was acceptable for ADHD diagnosis $(\mathrm{kappa}=.88)$ and for other disorders with $>5 \%$ base rate in the sample (all kappa>.68). Disagreements were conferenced. If consensus was not readily achieved, the participant was excluded.

\section{Exclusion Criteria}

After a phone screening, adolescents were excluded if they exhibited neurological impairments or were taking long-acting, non-stimulant psychotropic medications. Additionally, participants were excluded if they had a history of seizures or head injury with loss of consciousness, a history of substance abuse, and a prior diagnosis of an intellectual disability, autism spectrum disorder, or psychosis. Participants were also excluded if they were currently experiencing a depressive episode or had an IQ under 70. 


\section{Medication Use}

Participants were included in the study if they were prescribed stimulant medications for ADHD ( $\mathrm{n}=194)$ but were required to be on medication washout lasting 24 hours for short-lasting medications or 48 hours for long lasting medications prior to any testing visits. Children taking non-stimulant medications were excluded from the study.

\section{Prior ADHD Diagnosis}

During the phone screening process, parents were asked if child had a prior diagnosis from a practitioner in the community and this measure was used to evaluate sex differences in the rates of community diagnosis.

\section{EEG Recording and Analysis}

272 individuals $(\mathrm{ADHD}=162)$ from this sample were then recruited and asked to complete one additional EEG testing visit at either Year 5, 6, or 8 of the longitudinal study depending on date of initial enrollment. Identical to previous publication (Alperin et al., 2019), resting state EEG was recorded for four, two-minute alternating blocks of eyes closed (EC) and eyes open (EO) conditions (EC, EO, EC, EO). EEG was recorded at 500Hz with $32 \mathrm{Ag}-\mathrm{AgCl}$ active electrodes using Pycorder v1.0.9 and impedance for all electrodes were at or below 50k $\Omega$ $($ mean $=23 \mathrm{k} \Omega)$. The electrode array was based on the international 10-20 system centered at $\mathrm{Cz}$. EEG signals were amplified by a BrainVision actiCHamp2 amplifier (Cary, NC). Recordings were referenced to $\mathrm{Cz}$ online then re-referenced offline.

EEG data were analyzed using ERPLAB and EEGLAB toolboxes for MATLAB. This included resampling raw EEG data to $250 \mathrm{~Hz}$, re-referencing offline to the average of all channels, filtering EEG signals with an IIR bypass filter, and removing eye artifacts through 
independent component analysis. The data was segmented into 2-s non-overlapping epochs with the total number of epochs being 240. If a trial contained baseline drift or movement artifacts greater than $90 \mu \mathrm{V}$, they were discarded from the analysis. If greater than $20 \%$ of epochs were flagged following artifact rejection, individual channels were interpolated; channels responsible for the greatest percentage of trial removal were interpolated one at a time until less than $20 \%$ of total epochs were rejected. Due to a priori threshold of $50 \%$, no subjects were removed from analyses for having too few epochs.

Power from the alpha band $(8-13 \mathrm{~Hz})$ was also extracted for each subject. In order to increase normality, each electrode site was used to calculate the natural log of alpha power values. Alpha asymmetry was then calculated by subtracting the alpha power of leftward electrode sites from their corresponding electrode on the right side (for example: $\ln (\mathrm{F} 8)-\ln (\mathrm{F} 7)$ and $\ln (\mathrm{F} 4)-\ln (\mathrm{F} 3))$. Based on previous findings in literature, analyses were completed for frontal effects using two electrode pairs (F4/3, F8/7) and posterior effects using two electrode pairs (P4/3, P8/7). Due to alpha asymmetry being highly correlated for EC and EO conditions, values from each condition were then averaged together in order to complete a final alpha asymmetry score for all electrode pairs.

\section{Statistical Analysis}

All statistical analyses were carried out in SPSS v. 24 and included a series of ANOVA's and $\chi^{2}$ tests on prior diagnosis and expert consensus diagnosis, as well as frontal and posterior alpha asymmetry. 


\section{RESULTS}

\section{Full Sample Description}

Participants with $(n=301)$ and without ADHD ( $=509)$ significantly differed in age $(p=.03)$ and those diagnosed with ADHD had a lower IQ score compared to controls $(p<.001)$. In line with current rates of ADHD diagnosis in community-based samples of the population, there was a significant relationship between sex and ADHD diagnosis status $(\mathrm{p}<.001)$.

\begin{tabular}{|l|l|l|l|}
\hline Variable & Control & ADHD & Significance \\
\hline $\mathrm{n}$ & 301 & 509 & - \\
\hline Sex (male:female) & & & $\mathbf{p}<.001$ \\
\hline Age (years) & $9.48(1.59)$ & $9.72(1.52)$ & $\mathbf{p = . 0 3}$ \\
\hline IQ & $115.28(12.7)$ & $108.27(13.87)$ & $\mathbf{p}<.001$ \\
\hline $\begin{array}{l}\text { Connors Inattention } \\
\text { T-score }\end{array}$ & $47.14(7.5)$ & $74.77(11.56)$ & $\mathbf{p}<.001$ \\
\hline $\begin{array}{l}\text { Connors Hyperactivity } \\
\text { T-score }\end{array}$ & $47.59(8.73)$ & $71.93(14.89)$ & $\mathbf{p}<.001$ \\
\hline
\end{tabular}

Table 1: Demographics of the sample

\section{Prior ADHD Diagnosis}

After subthreshold cases were removed for statistical analyses, 280 children had a previous ADHD diagnosis (males=197) out of the entire sample. Of these, males were significantly more likely than females to have received a prior ADHD diagnosis in the community $\left(X^{2}(1)=13.3, p<.001\right)$. Based on ratios described in prior literature, there was approximately a 1.76:1 diagnosis ratio. 
Females with a prior ADHD diagnosis $(\mathrm{M}=7.58, \mathrm{SD}=1.80)$ had more inattention symptoms than males with a prior $\mathrm{ADHD}$ diagnosis $(\mathrm{M}=7.07, \mathrm{SD}=1.81)(t(278)=-2.15, p=.03)$. The sexes did not significantly differ when it came to hyperactive-impulsive symptom counts $(p=.43)$ or the reported impairment from symptoms $(p=.28)$.

\begin{tabular}{|c|c|c|c|c|c|c|}
\hline & \multicolumn{2}{|c|}{ Males $(n=519)$} & \multicolumn{2}{|c|}{ Females $(n=322)$} & \multirow[b]{2}{*}{$X 2(d f)$} & \multirow[b]{2}{*}{$p$} \\
\hline & $n$ & $\%$ & $n$ & $\%$ & & \\
\hline Prior Diagnosis & & & & & $13.28(1)$ & $<.001$ \\
\hline ADHD & 197 & 38 & 83 & 25.78 & & \\
\hline Control & 322 & 62 & 239 & 74.22 & & \\
\hline
\end{tabular}

Table 2: Group Differences in Prior Diagnosis Status

\section{Expert Diagnosis}

Once subthreshold cases were removed for statistical analyses, 509 children and adolescents were shown to meet criteria for an expert ADHD diagnosis (males=359). Similar to previous results for prior ADHD diagnosis, males were also significantly more likely than females to have received an expert consensus ADHD diagnosis $\left(X^{2}(1)=39.1, p<.001\right)$. Based on prior literature, there was approximately a 2.5:1 diagnosis ratio.

Among those with an expert ADHD diagnosis, males $(\mathrm{M}=5.07, \mathrm{SD}=2.51)$ had more hyperactive-impulsive symptoms than females $(\mathrm{M}=4.49, \mathrm{SD}=2.8)(t(507)=2.29, p=.02)$ but groups marginally differed when it came to inattention symptom counts $(t(507)=-1.77, p=.08)$. There were also no differences in reported impairment from symptoms $(p=.82)$. 


\begin{tabular}{|c|c|c|c|c|c|c|}
\hline & \multicolumn{2}{|c|}{ Males $(n=505)$} & \multicolumn{2}{|c|}{ Females $(n=305)$} & \multirow[b]{2}{*}{$X 2(d f)$} & \multirow[b]{2}{*}{$p$} \\
\hline & $n$ & $\%$ & $\mathrm{n}$ & $\%$ & & \\
\hline Expert Diagnosis & & & & & 39.09 (1) & $<.001$ \\
\hline ADHD & 359 & 71.09 & 150 & 49.18 & & \\
\hline Control & 146 & 28.91 & 155 & 50.82 & & \\
\hline
\end{tabular}

Table 3: Group Differences in Expert ADHD Diagnosis Status

\section{Overlap of Prior Diagnosis and}

Crosstabulation analysis was completed to determine if a relationship exists between prior ADHD diagnosis and expert consensus ADHD diagnosis variables. For males, variables agreed that 141 children do not meet criteria for ADHD and 194 children do meet criteria. Expert consensus diagnosis believed 162 additional children should meet criteria for ADHD diagnosis, and previous diagnosis believed 2 additional children should.

For females, both variables agreed that 153 children do not meet criteria for ADHD diagnosis and 82 children do meet criteria. Expert consensus diagnosis believed 68 additional children should meet criteria for ADHD diagnosis, and previous diagnosis did not believe any additional children should.

\begin{tabular}{|l|l|r|r|}
\hline \multicolumn{2}{|c|}{} & \multicolumn{2}{c|}{$\begin{array}{c}\text { Previous } \\
\text { Diagnosis }\end{array}$} \\
\cline { 3 - 4 } \multicolumn{2}{|c|}{} & Control & ADHD \\
\hline \multirow{3}{*}{ Expert Diagnosis } & Control & 141 & 2 \\
\cline { 2 - 4 } & ADHD & 162 & 194 \\
\hline
\end{tabular}

Table 4: Crosstabulation of Males

\begin{tabular}{|l|l|r|r|}
\hline \multicolumn{2}{|c|}{} & \multicolumn{2}{c|}{$\begin{array}{c}\text { Previous } \\
\text { Diagnosis }\end{array}$} \\
\cline { 3 - 4 } \multicolumn{2}{|c|}{} & Control & ADHD \\
\hline \multirow{2}{*}{ Expert Diagnosis } & Control & 153 & 0 \\
\cline { 2 - 4 } & ADHD & 68 & 82 \\
\hline
\end{tabular}

Table 5: Crosstabulation of Females 


\section{Alpha Asymmetry}

For frontal alpha asymmetry in the expert diagnosis group, there was a marginal sex effect found, $\mathrm{F}(1,222)=2.44, p=.12, \mathrm{~d}=.2$, with females showing more leftward asymmetry in both the ADHD and control groups. There was no significant relationship between ADHD diagnosis and frontal alpha asymmetry $(p=.45)$ and no ADHD diagnosis $\mathrm{x}$ sex interaction at frontal electrode sites $(p=.43)$.

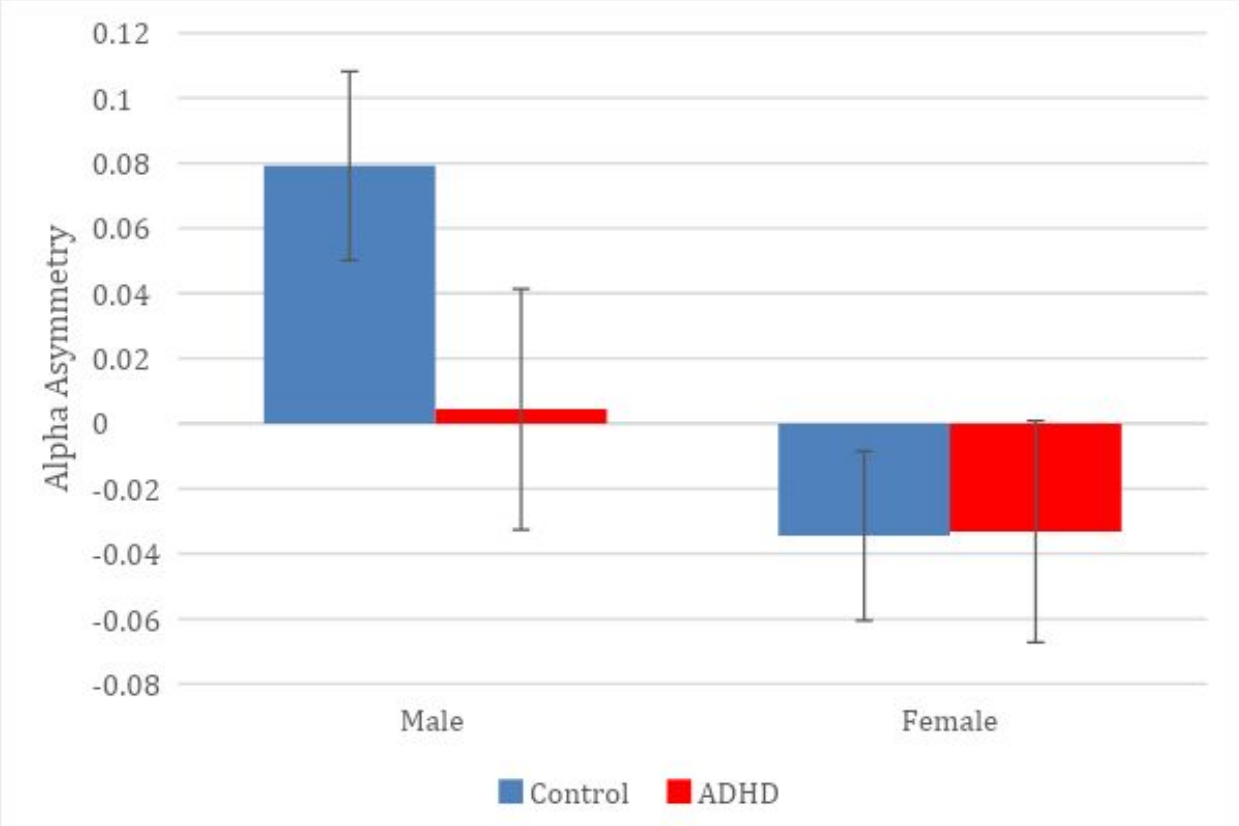

Figure 1: Group Differences in Frontal Alpha Asymmetry

Posterior analysis yielded similar results. For posterior alpha asymmetry, there was also a marginal sex effect found, $\mathrm{F}(1,222)=2.37, p=.13, \mathrm{~d}=.22$, but with females showing less rightward asymmetry than males in both groups. There was no significant relationship between ADHD diagnosis and posterior alpha asymmetry $(\mathrm{p}=.41)$ and no ADHD diagnosis $\mathrm{x}$ sex interaction at posterior sites $(p=.23)$. 


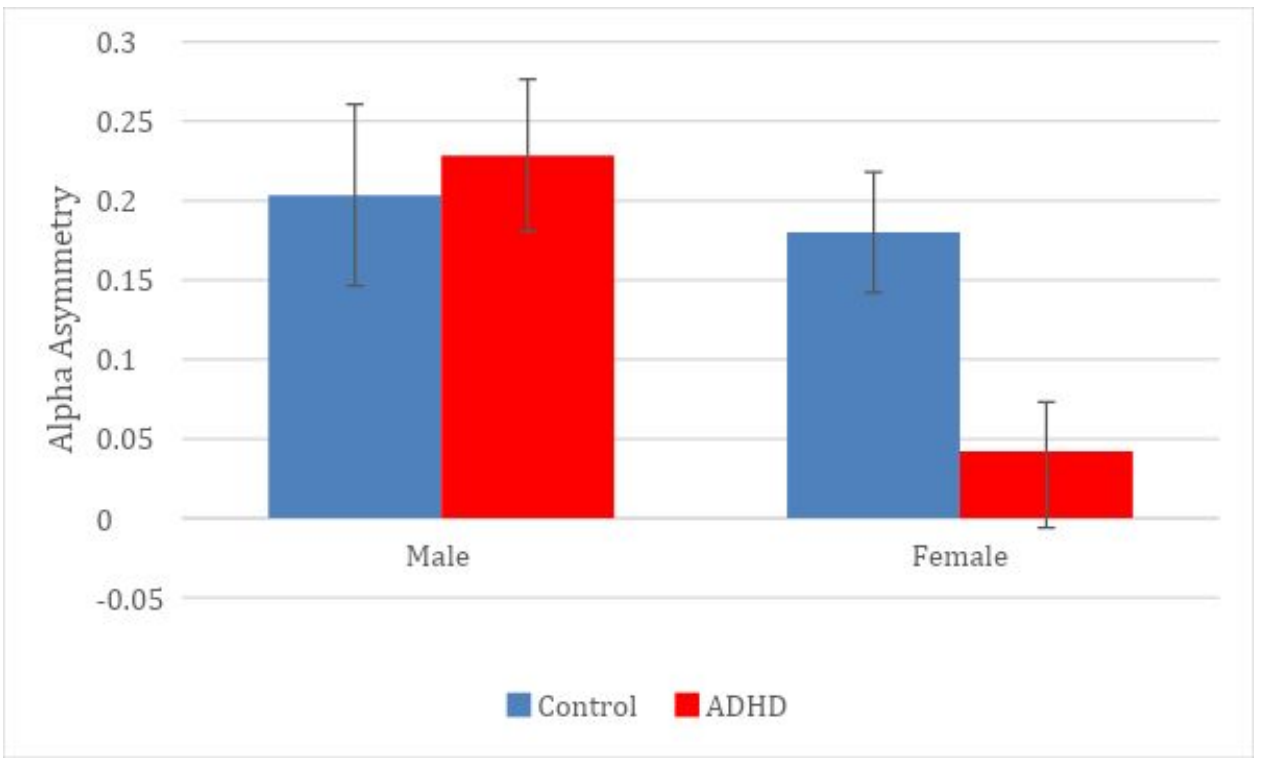

Figure 2: Group Differences in Posterior Alpha Asymmetry

\section{DISCUSSION}

The current study examined if there were significant sex-based differences when it came to ADHD diagnosis rates in both prior diagnosis and expert consensus diagnosis. This study also examined if neurophysiological sex differences exist in adolescents with ADHD, specifically alpha asymmetry at frontal and posterior electrode sites. Overall, results are consistent with previously made hypotheses, though with a few important differences worth noting.

Results showed that males were significantly more likely than females to have received a previous ADHD diagnosis from a practitioner in the Portland community. Based on prior research that presents this as a diagnosis ratio, this was approximately $1.76: 1$. This finding is interesting as the ratio that is typically found in clinic-referred samples is 9:1 (American Psychiatric Association, 1994), so our findings differ despite there being a significant sex based difference still present. One finding that is consistent with previous literature however is females had overall higher inattention symptom counts compared to males, though didn't significantly 
differ in hyperactive and impulsive symptom counts; this is possibly consistent with the hypothesis that females require more severe symptoms in order to be diagnosed with ADHD by clinic referral (Gershon, 2002) and that more hyperactive females may be referred as well. However, contradictory to this, males and females did not significantly differ when considering the overall impairment of the problems.

The measure used to identify children as having a previous ADHD diagnosis may be a limitation though as they may not be representative of the typical referred population. It is possible that when recruiting using a broad community-based sampling procedure, respondents were parents that were concerned about their children's behavior and were seeking a potential diagnosis or explanation, and this may not have captured all of those children who already had a previous diagnosis. This may also be an explanation for the $1.76: 1$ clinic-referred ratio as well.

Results from expert consensus diagnosis proved to be similar. In this set of children, males were also significantly more likely to receive an ADHD diagnosis than females, though the ratio found was approximately $2.5: 1$. This ratio is closer to what was expected based on prior literature (Willcutt, 2012) compared to those with a previous ADHD diagnosis. Considering the fact that referral bias can be eliminated as a potential explanation for this discrepancy, and that the ratio was more closely related to what has been found in previous literature, this finding may support the hypothesis that there is a valid difference in the amount of males and females that present with ADHD (Willcutt, 2012). If this were the case, then referral bias to clinical settings would only exacerbate this difference, leading to the 9:1 ratio seen in those research samples.

Additionally, in this subset of children, the sexes also significantly differed in hyperactive and impulsive symptom counts, with males showing this more than females; the opposite was 
true with inattentive symptom counts. This is in line with previous literature that suggests there is a sex difference in overall symptom presentation of the disorder (Gaub \& Carlson, 1997; Gershon, 2002; Quinn, 2008) with males showing more hyperactive symptoms and females showing more inattention symptoms. However, like findings for those with a previous diagnosis, the sexes did not differ when it came to the overall impairment of the problems either. One possible explanation for this is that females may not be diagnosed with ADHD until their symptoms become more difficult to manage at a later age. Completing similar analyses on later years of the study with the same children in the future would be beneficial.

Statistical analysis also revealed that experts forming a consensus diagnosis were able to identify significantly more males and females as having ADHD than those relying on community referral. In this analysis, it was shown that 162 males who did not have a previous ADHD diagnosis met criteria for one, and this was also the case for 68 more females. Additionally, there were two children that had a previous ADHD diagnosis that no longer met criteria to receive one at that point in the longitudinal study. This is important because while there may be a significant sex difference regarding rates of ADHD diagnosis in both samples, this finding suggests that experts contributing to a consensus diagnosis are still identifying more children overall as meeting the proper criteria for a formal ADHD diagnosis.

Regarding neurophysiological sex differences, findings were marginal, and as such all results should be considered with caution. In analyses for alpha asymmetry at frontal electrode sites, there was a marginal effect of sex on the data with females showing a more leftward asymmetry than males. This is consistent with previous findings (Karalunas et. al., 2019; Allen et. al., 2004; Baving et. al., 2003; Davidson, 1998; Diego et. al., 2001; Santesso et. al., 2006; 
Thibodeau et. al., 2006) as females present with more negative affective disorders and symptoms that may be characterized by a leftward alpha asymmetry. However, there was not a significant relationship between ADHD diagnosis and frontal alpha asymmetry, and no interaction between sex and ADHD diagnosis status either.

These findings were virtually the same when it came to posterior electrode sites, though females did not show a leftward asymmetry but a less rightward one. This finding is inconsistent with previous literature (Hale et al., 2009, 2010) that have found significant posterior effects, though additional research is needed to clarify a possible theoretical interpretation. Considering that these findings are marginal, and that previous findings in literature are considered mixed, potential neurophysiological biomarkers such as alpha asymmetry that account for sex differences in ADHD require further evaluation. Additionally, considering the heterogeneity of ADHD as a psychiatric disorder, it may be wise to move from attempting to identify one endophenotype for ADHD to identifying endophenotypes for certain individuals under specific circumstances.

\section{Limitations}

There are a couple more limitations to consider for this project. First, current analyses used an average reference when calculating alpha asymmetry. While this is consistent with other studies (Alperin et. al., 2019; Gordon et. al., 2010; Keune et. al., 2015), using a Cz reference could potentially affect the reliability of the found results (Coan \& Allen, 2003). Other references have been used in a variety of other studies, though some work suggests that findings across multiple approaches have similar findings (Coan \& Allen, 2003). Along those same lines, this study focuses on the use of frontal alpha asymmetry as a potential neurobiological marker 
for ADHD, though future studies may want to consider other EEG measures given mixed findings to date. Additionally, researchers will need to consider the heterogeneity of ADHD while doing so as there are multiple moderators contributing to findings thus far.

It is also important to consider that while significant findings were present in the current study, it is difficult to agree on one 'true' or best explanation as to why. Specifically, significant findings could potentially be attributed to innate biological differences that exist between the sexes, but it could also be because of the reflection of societal gender roles as well. While there is a tendency in the field to attribute neurobiological findings to innate biological processes, it is important to consider that socialization could affect findings as well; socialization itself has the ability to affect brain development, and thus we should also consider the possibility that the differences in socialization between the sexes from birth could affect research findings. However, it is difficult to separate these possibilities and this caveat should be kept in mind when considering the data presented in this study.

\section{Conclusions}

This study found that there was a significant relationship between sex and ADHD diagnosis rates, with males being significantly more likely to receive both a prior ADHD diagnosis and an expert consensus diagnosis. Females showed greater inattention symptom counts in both measures, and males showed greater hyperactive and impulsive symptom counts in only expert consensus diagnosis; the sexes did not differ when it came to reported impairment, however. Lastly, there was a marginal sex effect on frontal alpha asymmetry and a marginal sex effect on posterior sites as well, suggesting that sex specific biomarkers require further evaluation. 


\section{REFERENCES}

Albrecht, B., Brandeis, D., Uebel, H., Heinrich, H., Heise, A., Hasselhorn, M., Rothenberger, A., Banaschewski, T. (2010). Action monitoring in children with or without a family history of ADHD - Effects of gender on an endophenotype parameter. Neuropsychologia, 48(4), 1171-1177.

Allen, J.J., Coan, J.A., Nazarian, M. (2004a). Issues and assumptions on the road from raw signals to metrics of frontal EEG asymmetry in emotion. Biological Psychology, 67, 183 218.

Alperin, B., Smith, C., Gustafsson, H., Figuracion, M., \& Karalunas, S. (2019). The relationship between alpha asymmetry and ADHD depends on negative affect level and parenting practices. Journal of Psychiatric Research, 116, 138-146.

American Psychiatric Association. (1994). Diagnostic and statistical manual of mental disorders (4th ed.). Washington, DC: Author.

Arnett, A. B., Pennington, B. F., Willcutt, E. G., DeFries, J. C., \& Olson, R. K. (2015). Sex differences in ADHD symptom severity. Journal of Child Psychology and Psychiatry, 56(6), 632-639.

Barry, R., Clarke, A., Mccarthy, R., Selikowitz, M., Johnstone, S., Hsu, C., Bond, D., Wallace, M. J., Magee, C. (2005). Age and gender effects in EEG coherence: II. Boys with attention deficit/hyperactivity disorder. Clinical Neurophysiology, 116(4), 977-984.

Barry, R., Clarke, A., Mccarthy, R., \& Selikowitz, M. (2006). Age and gender effects in EEG coherence: III. Girls with attention-deficit/hyperactivity disorder. Clinical Neurophysiology, 117(2), 243-251.

Baving, L., Laucht, M., \& Schmidt, M. (2002). Frontal brain activation in anxious school children. Journal of Child Psychology and Psychiatry, 43(2), 265-274.

Biederman, J., Mick, E., Faraone, S. V., Braaten, E., Doyle, A., Spencer, T., Wilens, T. E., Frazier, E., Johnson, M. A. (2003). Influence of gender on attention deficit hyperactivity disorder in children referred to a psychiatric clinic. (Article). American Journal of Psychiatry, 159(1), 36-42. 
Biederman, J., Ball, S., Monuteaux, M., Mick, E., Spencer, T., Mccreary, M., Cote, M., Faraone, S. (2008). New Insights Into the Comorbidity Between ADHD and Major Depression in Adolescent and Young Adult Females. Journal of the American Academy of Child \& Adolescent Psychiatry, 47(4), 426-434.

Clarke, A., Barry, R., Mccarthy, R., \& Selikowitz, M. (2001). Age and sex effects in the EEG: Differences in two subtypes of attention-deficit/hyperactivity disorder. Clinical Neurophysiology, 112(5), 815-826.

Coan, J.A., Allen, J.J.B. Frontal EEG asymmetry and the behavioral activation and inhibition systems. Psychophysiology, 40, 106-114.

Conners, C. K. (2001). Conners Rating Scale Revised Technical Manual.

Davidson, R.J. (2004). What does the prefrontal cortex "do" in affect: perspectives on frontal alpha asymmetry research. Biological Psychology, 67, 219-233.

Davidson, R.J. (1998). Anterior electrophysiological asymmetries, emotions, and depression: conceptual and methodological conundrums. Psychophysiology, 35, 607-614.

Diego, M.A., Field, T., Hernandez-Reif, M. (2001). CES-D depression scores are correlated with frontal EEG alpha asymmetry. Depression Anxiety, 13, 32-37.

Doyle, A., Faraone, S., Seidman, L., Willcutt, E., Nigg, J., Waldman, I., Pennington, B., Peart, J., Biederman, J. (2005). Are endophenotypes based on measures of executive functions useful for molecular genetic studies of ADHD? Journal of Child Psychology and Psychiatry, 46(7), 774-803.

DuPaul, G., Anastopoulos, J., Power, A., Reid, D., Ikeda, T., \& McGoey, R. (1998). Parent Ratings of Attention-Deficit/Hyperactivity Disorder Symptoms: Factor Structure and Normative Data. Journal of Psychopathology and Behavioral Assessment, 20(1), 83-102.

Dupuy, F., Barry, R., Clarke, A., Mccarthy, R., \& Selikowitz, M. (2013). Sex differences between the combined and inattentive types of attention-deficit/hyperactivity disorder: An EEG perspective. International Journal of Psychophysiology, 89(3), 320-327.

Dupuy, F., Clarke, A., Barry, R., Mccarthy, R., \& Selikowitz, M. (2008). EEG coherence in girls 
with Attention-Deficit/Hyperactivity Disorder: Stimulant effects in good responders. International Journal of Psychophysiology, 70(3), 151-157.

Dupuy, F., Clarke, A., Barry, R., Mccarthy, R., \& Selikowitz, M. (2014). EEG Differences Between the Combined and Inattentive Types of Attention-Deficit/Hyperactivity Disorder in Girls: A Further Investigation. Clinical EEG and Neuroscience, 45(4), 231237.

Dupuy, F., Clarke, A., Barry, R., Mccarthy, R., \& Selikowitz, M. (2011). Girls with Attention-Deficit/Hyperactivity Disorder: EEG Differences between DSM-IV Types. Clinical EEG and Neuroscience, 42(1), 1-5.

Ellis, A.J., Kinzel, C., Salgari, G.C., Loo, S.K. (2017). Frontal alpha asymmetry predicts inhibitory processing in youth with attention deficit/hyperactivity disorder. Neuropsychologia, 102, 45-51.

Faraone, S., Biederman, J., Spencer, T., Wilens, T., Seidman, L., Mick, E., \& Doyle, A. (2000). Attention-deficit/hyperactivity disorder in adults: An overview. Biological Psychiatry, $48(1), 9-20$.

Froehlich, T., Lanphear, B., Epstein, J., Barbaresi, W., Katusic, S., \& Kahn, R. (2007). Prevalence, Recognition, and Treatment of Attention-Deficit/Hyperactivity Disorder in a National Sample of US Children. Archives of Pediatrics \& Adolescent Medicine, 161(9), 857-864.

Gaub, M., \& Carlson, C. (1997). Gender Differences in ADHD: A Meta-Analysis and Critical Review. Journal of the American Academy of Child \& Adolescent Psychiatry, 36(8), 1136-1139.

Gershon, J. (2002). A Meta-Analytic Review of Gender Differences in ADHD. Journal of Attention Disorders, 5(3), 143-154.

Goodman, R. (2001). Psychometric properties of the strengths and difficulties questionnaire. Journal of the American Academy of Child \& Adolescent Psychiatry, 40(11), 1337-1345.

Hale, T.S., Smalley, S.L., Dang, J., Hanada, G., Macion, J., McCracken, J.T., McGough, J.J., Loo, S.K. (2010). ADHD familial loading and abnormal EEG alpha asymmetry in children with ADHD. Psychiatric Research, 44, 605-615. 
Hale, T.S., Smalley, S.L. Hanada, G., Macion, J., McCracken, J.T., McGough, J.J., Loo, S.K. (2009). Atypical alpha asymmetry in adults with ADHD. Neurophychologia, 47, 20822088.

Harmon-Jones, E., Allen, J.J. (1997). Behavioral activation sensitivity and resting frontal EEG asymmetry: covariation of putative indicators related to risk for mood disorders. $J$ Abnormal Psychology, 106, 159-163.

Harmon-Jones, E., Harmon-Jones, C., Amodio, D.M., Gable, P.A. (2011). Attitudes towards emotions. Personal Social Psychology, 101, 1332-1350.

Hartung, C. M., \& Lefler, E. K. (2019). Sex and gender in psychopathology: DSM-5 and beyond. Psychological bulletin.

Hermens, D., Kohn, M., Clarke, S., Gordon, E., \& Williams, L. (2005). Sex differences in adolescent ADHD: Findings from concurrent EEG and EDA. Clinical Neurophysiology, $116(6), 1455-1463$.

Hermens, D., Williams, L., Lazzaro, I., Whitmont, S., Melkonian, D., \& Gordon, E. (2004). Sex differences in adult ADHD: A double dissociation in brain activity and autonomic arousal. Biological Psychology, 66(3), 221-233.

Jonsdottir, S., Bouma, A., Sergeant, J., \& Scherder, E. (2006). Relationships between neuropsychological measures of executive function and behavioral measures of ADHD symptoms and comorbid behavior. Archives of Clinical Neuropsychology, 21(5), 383394.

Karalunas, S.L., Gustaffson, H.C., Fair, D., Musser, E.D., Nigg, J.T. (2019). Do we need an irritable subtype of ADHD? Replication and extension of a promising temperament profile approach to ADHD subtyping. Psychological Assessment, 31, 326-247.

Kessler, R., Adler, L., Barkley, R., Biederman, J., Conners, K., Demler, O., Faraone, S., Greenhill, L., Howes, M., Secnik, K., Spencer, T., Ustun, T., Waiters, E., Zaslavsky, A. (2007). The prevalence and correlates of adult ADHD in the United States: results from the national comorbidity survey replication. American Journal of Psychiatry, 163(4), 716-723. 
Keune, P.M., Wiedemann, E., Schneidt, A., Schonenberg, M. (2015). Frontal brain asymmetry in adult attention-deficit/hyperactivity disorder (ADHD): extending the motivational dysfunction hypothesis. Clinical Neurophysiology, 126, 711-720.

Kim, J. W., Kim, S. Y., Choi, J. W., Kim, K. M., Nam, S. H., Min, K. J., Young, S. L., Choi, T. Y., \& Tae Young. (2017). Differences in Resting-state Quantitative Electroencephalography Patterns in Attention Deficit/Hyperactivity Disorder with or without Comorbid Symptoms. Clinical Psychopharmacology and Neuroscience: The Official Scientific Journal of the Korean College of Neuropsychopharmacology, 15(2), 138-145.

Lazarro, I., Gordon, E., Li, W., Lim, C.L., Plahn, M., Whitmont, S., Clarke, S., Barry, R.J., Dosen, A., Meares, R. Simultaneous EEG and EDA measures in adolescent attention deficit hyperactivity disorder. International Journal of Psychophysiology, 34(2), 123-134.

Liotti, M., Pliszka, S., Perez, R., Luus, B., Glahn, D., \& Semrud-Clikeman, M. (2007). Electrophysiological correlates of response inhibition in children and adolescents with ADHD: Influence of gender, age, and previous treatment history. Psychophysiology, 44(6), 936-948.

March J., Parker, J., Sullivan, K., Stallings, P., Conners, C. (1997). The Multidimensional Anxiety Scale for Children (MASC): Factor structure, reliability, and validity. Journal of the American Academy of Child \& Adolescent Psychiatry. 1997; 36(4):554-565.

Mitchell, J.T. (2010). Behavioral approach in ADHD: testing a motivation dysfunction hypothesis. Journal of Attention Disorders, 13, 609-617.

Pelham, J., Fabiano, G., \& Massetti, G. (2005). Evidence-Based Assessment of Attention Deficit Hyperactivity Disorder in Children and Adolescents. Journal of Clinical Child \& Adolescent Psychology, 34(3), 449-476.

Robbie, J., Clarke, A., Barry, R., Dupuy, F., Mccarthy, R., \& Selikowitz, M. (2016). Coherence in children with AD/HD and excess alpha power in their EEG. Clinical Neurophysiology, 127(5), 2161-2166.

Santesso, D.L., Reker, D.L., Schmidt, L.A., Segalowitz, S.J. (2006). Frontal electroencephalogram activation asymmetry, emotional intelligence, and externalizing behaviors in 10-year-old children. Child Psychiatry, 36, 311-328. 
Seidman, L., Biederman, J., Monuteaux, M., Valera, E., Doyle, A., \& Faraone, S. (2005). Impact of Gender and Age on Executive Functioning: Do Girls and Boys With and Without Attention Deficit Hyperactivity Disorder Differ Neuropsychologically in Preteen and Teenage Years? Developmental Neuropsychology, 27(1), 79-105.

Skogli, E., Teicher, M., Andersen, P., Hovik, K., \& Oie,. (2013). ADHD in girls and boys gender differences in co-existing symptoms and executive function measures. $B M C$ Psychiatry, 13(1), 298.

Swanson, J., Deutsch, C., Cantwell, D., Posner, M., Kennedy, J. L., Barr, C. L., Moyzie, R., Schuck, S., Flodman, P., Spence, M. A., Wasdell, M. (2001). Genes and attention-deficit hyperactivity disorder. Clinical Neuroscience Research, 1(3), 207-216.

Thibodeau, R., Jorgensen, R.S., Kim, S. (2006). Depression, anxiety, and resting frontal EEG asymmetry: a meta-analytic review. Abnormal Psychology, 115, 715-729.

Quinn, P. (2008). Attention-deficit/hyperactivity disorder and its comorbidities in women and girls: An evolving picture. Current Psychiatry Reports, 10(5), 419-423.

Wilens, T., Biederman, J., Spencer, T. (2002). Attention-deficit/hyperactivity disorder across the lifespan. Annu Rev Med, 53, 113-131.

Willcutt, E.G. (2012). The prevalence of DSM-IV attention deficit/hyperactivity disorder: a meta-analytic review. Neurotherapeutics, 9, 490-499. 